\title{
Engineering Design in Five Weeks - Designing a Wind Chime
}

\author{
S. Scott Moor \\ Indiana University-Purdue University Fort Wayne
}

\begin{abstract}
Providing first-year students with a realistic engineering design experience is both difficult and desirable. The benefits of hands-on projects to student learning and to student interest are well documented. However, it is a challenge to pose simple design problems that include both engineering analysis and engineering synthesis. The construction of a wind chime provides an excellent and yet quick engineering design problem for first-year students. This project can be completed with inexpensive and readily available tools and materials. It provides opportunities for the students to use good engineering analysis in their designs and opportunities for students to exercise creativity.

Wind chimes have been proposed and used as a project or laboratory in a number of physics and mathematics courses. In this paper I review the approach and results of using a wind chime design in a first-year "Introduction to Engineering Design" course. In a portion of this course students are asked to design, construct and test a wind chime. They are provided with an equation to predict the frequency of their chimes that is based on a solution to the fourth-order wave equation. Students select their desired chime notes and use the equation to design their chimes. Using this equation requires simple calculation, care with units and the use of physical property data. They can vary the material, shape and size of their chimes.
\end{abstract}

Students use a computer to record the tones generated by their chimes and then analyze the frequencies that they produce in MATLAB. They are provided with a MATLAB function that produces a Fourier power spectrum of their recorded sound. In lecture, students are given background in musical notes, the vibration of rods and tubes, and a conceptual introduction to Fourier transform analysis.

In addition to the prediction of frequency students consider the quality of the tone produced. In particular, how their chime is suspended affects the quality of the resulting ring. At this point they are introduced to the concept and importance of a node for a standing wave device. They are told that the predicted location of the first node is $22.4 \%$ from one end of the tube.

This simple project includes subject matter from material science and engineering, acoustics, signal processing, experimentation, and computer programming. In addition issues of project planning and project reporting are addressed. While maintaining an open-ended project with plenty of room for creativity, this project is a simple engineering design project that goes beyond conceptual, and trial and error approaches.

\section{Background}

It is a common feature of many first-year engineering courses to include an open-ended project. These projects are desirable for many reasons. They are more realistic to engineering practice 
than simply assigning textbook analysis problems because they include many "soft skills" as well as analytic skills. They are often more interesting to first-year students and can be helpful with retention issues. The active (hands-on) nature makes them better learning experiences than traditional lecture content.

However it is difficult to find projects which encompass the breadth of engineering skills including engineering science, project management, group interaction, technical communication, spatial thinking and layout, creative problem solving, etc. It is particularly difficult in the firstyear due to the lack of maturity in engineering analysis and in life experience. Various programs have taken different strategies to implementing projects in the first year. Some programs have opted to include laboratory experiences, ${ }^{1,2}$ reverse engineering, ${ }^{3}$ or design projects. $^{4,5,6}$ In many cases programs will use some mix of these three strategies.

For our first-year "Introduction to Design" course I was interested in a design project which was open-ended and yet still included some concrete engineering analysis. Particularly I wanted a project that was:

1. accessible to a first-year engineering student

2. includes both creative design and concrete analytical work

3. demonstrates the need for iteration in design

4. requires physical/spatial reasoning

5. easily constructed and tested by students with minimal resources

Designing and building wind chimes meet these goals well. The students must select their desired notes, and the basic chime material. They must select materials and design the layout of the support structure, the "hammer" and the "sail". Simple theory is available that can predict the chime notes with reasonable accuracy. Students can measure their chime "notes" using a computer microphone and a simple MATLAB ${ }^{\mathrm{TM}}$ function. The theory can easily be adapted based on the test results to produce improved predictions.

There are several examples in the literature of wind chimes being used in introductory physics courses. Baxter and Hagenbuch ${ }^{7}$ provide a brief but complete discussion of using wind chimes in an introductory physics class. They include most of the important background theory. Their focus is to understand standing waves in a context other than the simple vibrating string. Harris ${ }^{8}$ describes a simple set of experiments used in a high school physics class where students examine the best place to hold a simple chime and the relationship between length and frequency. Oliver ${ }^{9}$ provides a set of instructions for making a full octave set of wind chimes from electrical conduit.

This paper outlines the use of wind chimes as a design project in an Introduction to Engineering Design course.

\section{Web Resources}

There are a large number of simple sites on the World Wide Web that include basic information on making wind chimes. I refer students to Brian Suits' web site, from Michigan Technological University, for a quick overview of building and understanding wind chimes. ${ }^{10}$ 
The Chuck's Chimes website, which one of my students located, reviews the basic theory of wind chimes plus a discussion of finding an ideal length for a tube where the frequency produced by the tube matches a fundamental frequency of the air column inside the tube. ${ }^{11}$ This page also includes a tube length calculator and some example wind chime designs. A range of other sites review the basic equations and give information on people's experience building wind chimes. They range from a retired engineer's web page to that for a middle school math teacher. ${ }^{12-15}$

Web sites are available that can be help students with selecting notes for their wind chime. The Grace Notes Windchimes' website includes recordings of various wind chimes they sell with specification of what notes are used in each chime. ${ }^{16}$ Michael Furstner's Jaz Class web site has a brief explanation of many common scales and cords including the major and minor pentatonic scales that are most commonly used in wind chimes. The site includes example wave files of the scales played on a piano and a listing of the notes in the scale for all twelve keys. ${ }^{12}$

\section{Project Details:}

Students in groups of three or four are asked to design, build and test a wind chime with at least five chimes. They are asked to demonstrate the stages in the design process outlined in their textbook ${ }^{19}$ and to include some iteration in their design. Particularly they are asked to select target notes, predict the tube size required to obtain the desired notes and build those tubes. They are then asked to test their chimes and correct their design based on test results.

This project allows students to experience a wide range of design issues. Students must consider the application, i.e., what notes will be interesting and appealing. They can use solid engineering science theory to predict the required length of the tubing. They use simple Fourier spectrums to test their resulting tubes. Students must design the tubing hanger and sail which requires consideration of practical and geometric issues. Through-out there are many creative and aesthetic issues to consider.

Construction of the wind chimes is fairly simple and inexpensive. Steel conduit or copper water pipe available at most any hardware store can be used to build the chimes. Type L and M copper pipe have different wall thicknesses which allow for further variation. Students can also check with metal distributors for a wider range of materials. Smaller diameter tubing (less than 2 inches in diameter) can easily be cut using an inexpensive and safe tubing cutter. The top support plate, the "ringer" and the "sail" can be made with wood or other simple materials using a drill, scroll saw and simple hand sanding.

I set up the student groups using a jigsaw approach. The week before beginning the project, students are surveyed about their background in music, their shop experience and their access to shop equipment. A copy of this survey is shown in appendix A. Then groups are set such that each group has at least one "music expert" and one "shop expert." This approach recognizes that students have different backgrounds in these areas and some will need help with either background in music or shop. Because we are primarily a commuter campus with a significant population of non-traditional students, many students have access to excellent shop facilities at home or at work. 
Students are asked to follow a project management scheme which is a modified version of that proposed by Moor and Drake. ${ }^{19}$ This project management setup includes setting group ground rules, setting and maintaining a schedule, and completing weekly project meetings and memos. At the end of five weeks, students present their work in class including a demonstration of their chimes and submit a written memo report. The final written report must include a design that is reproducible and must include drawings of the wind chime.

This project was used in the Fall 2004 "Introduction to Engineering Design" class at Indiana University - Purdue University Fort Wayne. This is the last of several first-year engineering classes, students have previously completed classes in both MATLAB and AUTOCAD. There were 27 students in the fall semester class.

In this class a series of short projects were used to allow students to have a variety of design experiences including both individual and group projects. In addition to this project, students had completed a quick paper design of a coffee delivery system, ${ }^{20}$ a toy glider design and a library research project.

\section{Lecture content:}

Project Management:

An initial in class session is used for students to develop ground rules for their groups, and to begin preparing a GANTT schedule for their project. In subsequent sessions students are introduced to a system of weekly project review meetings and memos where they set deliverables for the next week, assigning a primary person responsible for each deliverable, a due date and a priority to each deliverable. Each week they review their progress on these deliverables. Details on this type of approach are outlined in Moor and Drake. ${ }^{19}$

Introduction to sound \& music

Students are briefly introduced to some basic concepts of sound and music. The wave nature of sound and compression waves are reviewed. The basic characteristics of a musical note, its frequency, amplitude and shape are discussed. A chart of frequencies, such as that shown in Table 1 for an Equal Tempered Scale is provided and discussed. The idea that frequencies double every octave is noted.

Table 1: Frequencies $(\mathrm{Hz})$ for an Equal Tempered Scale $(\mathrm{A} 4=440 \mathrm{~Hz})$. Adapted from Suits ${ }^{10}$.

\begin{tabular}{|c|c|c|c|c|c|c|c|c|}
\hline Octave & $\mathbf{0}$ & $\mathbf{1}$ & $\mathbf{2}$ & $\mathbf{3}$ & $\mathbf{4}$ & $\mathbf{5}$ & $\mathbf{6}$ & $\mathbf{7}$ \\
\hline $\mathrm{C}$ & 16.35 & 32.7 & 65.41 & 130.81 & 261.63 & 523.25 & 1046.5 & 2093 \\
\hline $\mathrm{C}^{\#} / \mathrm{D}^{\mathrm{b}}$ & 17.32 & 34.65 & 69.3 & 138.59 & 277.18 & 554.37 & 1108.73 & 2217.46 \\
\hline $\mathrm{D}$ & 18.35 & 36.71 & 73.42 & 146.83 & 293.66 & 587.33 & 1174.66 & 2349.32 \\
\hline $\mathrm{D}^{\#} / \mathrm{E}^{\mathrm{b}}$ & 19.45 & 38.89 & 77.78 & 155.56 & 311.13 & 622.25 & 1244.51 & 2489.02 \\
\hline $\mathrm{E}$ & 20.6 & 41.2 & 82.41 & 164.81 & 329.63 & 659.26 & 1318.51 & 2637.02 \\
\hline $\mathrm{F}$ & 21.83 & 43.65 & 87.31 & 174.61 & 349.23 & 698.46 & 1396.91 & 2793.83 \\
\hline $\mathrm{F}^{\#} / \mathrm{G}^{\mathrm{b}}$ & 23.12 & 46.25 & 92.5 & 185 & 369.99 & 739.99 & 1479.98 & 2959.96 \\
\hline $\mathrm{G}$ & 24.5 & 49 & 98 & 196 & 392 & 783.99 & 1567.98 & 3135.96 \\
\hline $\mathrm{G}^{\#} / \mathrm{A}^{\mathrm{b}}$ & 25.96 & 51.91 & 103.83 & 207.65 & 415.3 & 830.61 & 1661.22 & 3322.44 \\
\hline $\mathrm{A}$ & 27.5 & 55 & 110 & 220 & 440 & 880 & 1760 & 3520 \\
\hline $\mathrm{A}^{\#} / \mathrm{B}^{\mathrm{b}}$ & 29.14 & 58.27 & 116.54 & 233.08 & 466.16 & 932.33 & 1864.66 & 3729.31 \\
\hline $\mathrm{B}$ & 30.87 & 61.74 & 123.47 & 246.94 & 493.88 & 987.77 & 1975.53 & 3951.07 \\
\hline
\end{tabular}


Wind chime background:

Students are provided with equation 1, Euler's equation for the ringing of a hollow chime. ${ }^{7}$ This equation is the solution to the fourth-order wave equation. The concepts of nodes and antinodes are discussed. They are informed that the first node is located $22.4 \%$ from the end of a tube or rod. This point is the ideal point to suspend the chime. The center of the rod forms an anti-node, making it an ideal place to strike the chime.

$$
f_{1}=\frac{(k L)_{1}^{2}}{2 \pi L^{2}} \sqrt{\frac{E I}{\rho A}}
$$

where:

$$
\begin{aligned}
& \mathrm{f}_{1}=\text { the primary frequency } \\
& (\mathrm{kL})_{1}=4.73 \\
& \mathrm{~L}=\text { length of the rod } \\
& \mathrm{E}=\text { Young's Modulus (Modulus of Elasticity) } \\
& \rho=\text { density of the material } \\
& \mathrm{A}=\text { cross sectional area } \\
& \mathrm{I}=\text { moment of area }
\end{aligned}
$$

It is important to be aware that for a vibrating tube the overtones are not simple harmonic multiples of the primary. They can be calculated by using different values for the constant $(\mathrm{kL})$, Table 2 lists the higher values of this constant.

Table 2: Values of the constant $(\mathrm{kL})_{\mathrm{i}}$ used for calculating overtones (adapted from Baxter and Hagenbuch $^{7}$ )

\begin{tabular}{|c|c|c|}
\hline Overtone & $\begin{array}{c}\text { Constant } \\
(\mathrm{kL})_{\mathrm{i}}\end{array}$ & $\begin{array}{c}\text { Ratio of overtones to primary } \\
(\mathrm{kL})_{\mathrm{i}}{ }^{2} /(\mathrm{kL})_{1}{ }^{2}\end{array}$ \\
\hline primary & 4.73 & 1 \\
\hline 2 & 7.85 & 2.75 \\
\hline 3 & 11 & 5.41 \\
\hline
\end{tabular}

Physical Properties and Area Moment of Inertia:

A brief discussion of physical properties is included particularly Young's Modulus and Density. Table 3 is provided with values for these two quantities. A brief conceptual discussion of the Area Moment of Inertia is included. I present that the area moment of inertial, $I=1 / 4 \pi \mathrm{r}^{4,} \mathrm{w}$ for a circular cross sectional area, where $\mathrm{r}$ is the radius and $\mathrm{I}=1 / 12 \mathrm{~s}^{4}$ for a square where $\mathrm{s}$ is the length of one side. Noting that superimposed moments can be added algebraically we derive the moment of inertia for an annulus. In equation 1, the moment of inertia is divided by the cross sectional area, dividing the resulting moment for an annulus by the area of the annulus results in equation 2.

$$
\frac{I}{A}=\frac{\left(r_{1}^{2}+r_{2}^{2}\right)}{4}
$$

where, where $r_{1}$ and $r_{2}$ are the inner and outer radius of the tube. This equation was included in the initial information provided the students so that they could get started and the explanation of its source presented later. 


\section{Working with Equations \& Units}

The above equations provide an excellent opportunity to review the basics of unit analysis and the metric system. Particularly students must understand how to work with the MPa units in the above equation. I take this opportunity to review unit systems and the analysis of units in an equation.

In discussing this equation we also review the importance of assumptions. In this case, key assumptions are: (1) that the tube vibrates freely in space, and (2) that the properties are uniform over its length and we have obtained the correct values for these properties. Both of these assumptions can become important in actual practice. The first assumption implies that we must hang the tubes in a manner which minimizes the impact on the tube's vibration. Hanging at the first node helps insure this assumption is not violated.

Table 3: Physical Properties for use in equation 1 (adapted from Callister ${ }^{21}$ )

\begin{tabular}{|l|l|l|}
\hline Material & $\begin{array}{l}\text { Young's Modulus } \\
\left(\mathrm{MPa} \times 10^{4}\right)\end{array}$ & $\begin{array}{l}\text { Density } \\
\left(\mathrm{Kg} / \mathrm{m}^{3}\right)\end{array}$ \\
\hline Aluminum & 6.9 & 2700 \\
\hline Brass & 10.1 & 8530 \\
\hline Copper & 11.0 & 8940 \\
\hline Magnesium & 4.5 & 1740 \\
\hline Nickel & 20.7 & 8900 \\
\hline Steel & 20.7 & 7800 \\
\hline
\end{tabular}

The second assumption is important when making the chimes from steel. Because steel is an alloy that can have varying properties due to alloy composition and treatment, the properties given for steel in Table 3 are probably not exact for the galvanized steel conduit that we get at the local hardware store.

To help deal with this problem, I introduce the concept of a lumped parameter model. In equation 1, if the tube material and cross section are held constant, only the frequency and the length vary. For this case all the other parameters can be lumped into a single adjustable parameter. Equation 3 results, where the frequency times the length squared is equal to a constant.

$$
\mathrm{fL}^{2}=\text { constant }
$$

Students are encouraged to use this lumped parameter model to analyze the results of their initial testing. If their initial test results are not as close as they would like to their desired notes they can (1) check to see that the value calculated in equation 3 is truly constant, and (2) they can use this constant to predict how much they need to modify their tube lengths.

\section{Fourier Transform Analysis}

Students are introduced to the concept of a Fourier Transform and the resulting Power Spectra without going into the details of the mathematics. This background includes a discussion of constructing a function out of a sine wave series and the review of some example Power Spectra. 
Students are instructed how to use the Windows Sound Recorder to record their chime as a .wav file. This includes a discussion of the concepts of sampling frequency and bit resolution. They can analyze the result using a provided MATLAB function which produces a power spectra from the first 4096 points in wav file (approximately $0.5 \mathrm{sec}$ of real time if recorded at a sampling rate of $8000 \mathrm{~Hz}$ ). The MATLAB function used was written by Mark Peterson a graduate student at the University of Colorado and is available on the web. ${ }^{22}$ Figure 1 shows an example graphical output from this function.
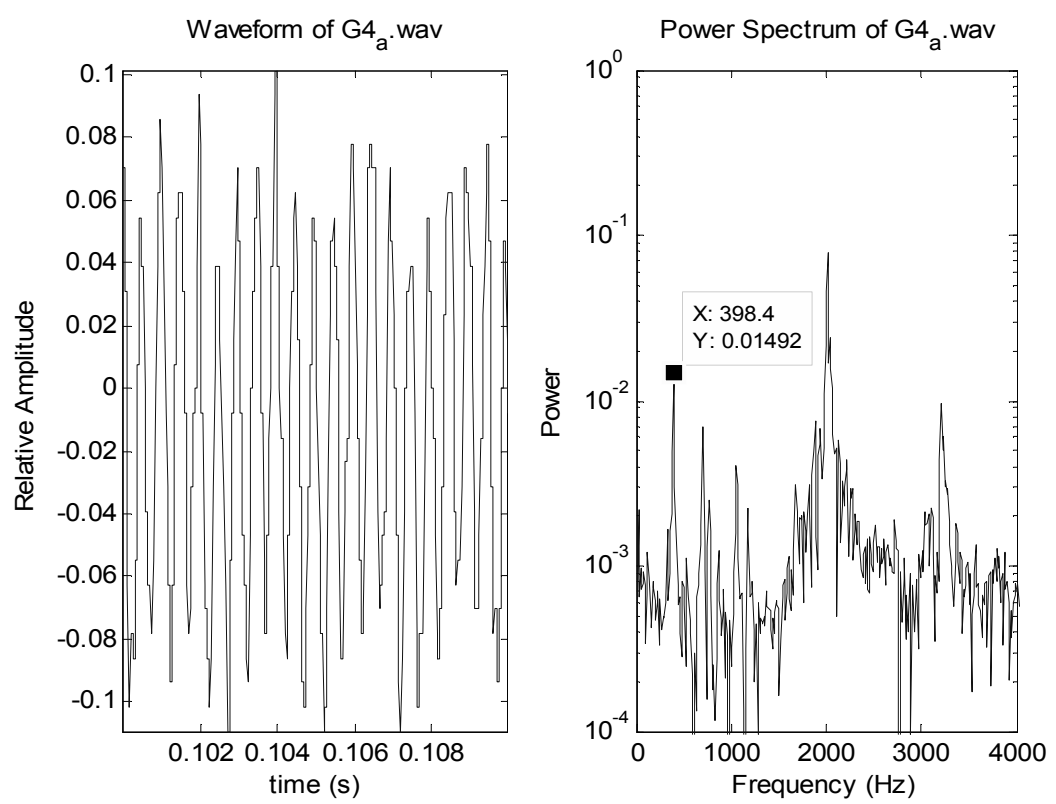

Figure 1: Output from Analyze function for a copper tube cut to be G4. The target nominal frequency is $392 \mathrm{~Hz}$. MATLAB's data curser is used to mark the primary peak with a measured frequency of $398 \mathrm{~Hz}$.

While this is a simple project it leads us to the discussion of a range of engineering issues. Most are important in all branches of engineering. This project easily leads to discussion of several specific engineering topics including the nature of materials, the vibration of solids, acoustics, and digital signal processing (DSP). The interesting topics of overtone prediction and measurement and the implied tone that can result from overtones were not addressed but could be interesting additions to the discussion. ${ }^{23}$

\section{Result}

All eight groups in the class completed this project in the time allotted, made good use of the theory presented and had varied and creative solutions to the problem. Figures 1-3 show three examples of the resulting chimes. The student variations shown in this figure include a chime with chemically accelerated patina development using a recipe from "The Complete Metalsmith" 24 and an example of some very detailed metal work on the sail. Students choose a variety of scales including both the major and minor pentatonic scale. One group chose to use tubes of three different diameters. Another group used very large diameter ( 2 inch OD) tubes and a toilet seat as the top support for the tubes! 
There were also unique aspects to each group's design process. Some groups identified and used additional web resources (some of which were included in the earlier section). One group chose to use an alternative sound recorder to get better wave files. One group developed a temporary pinch hanger made from a large hinge to allow them to test the tuning of their chimes without drilling a support hole. Most groups used CAD or solid modeling programs to lay out the top support and set the spacing of the chimes and used some software tools to carry out the repeated calculations with equation 1. These included Excel spreadsheets, MATLAB functions and MATHCAD worksheets. Many groups tested alternative sail and hammer designs to gain their desired result.

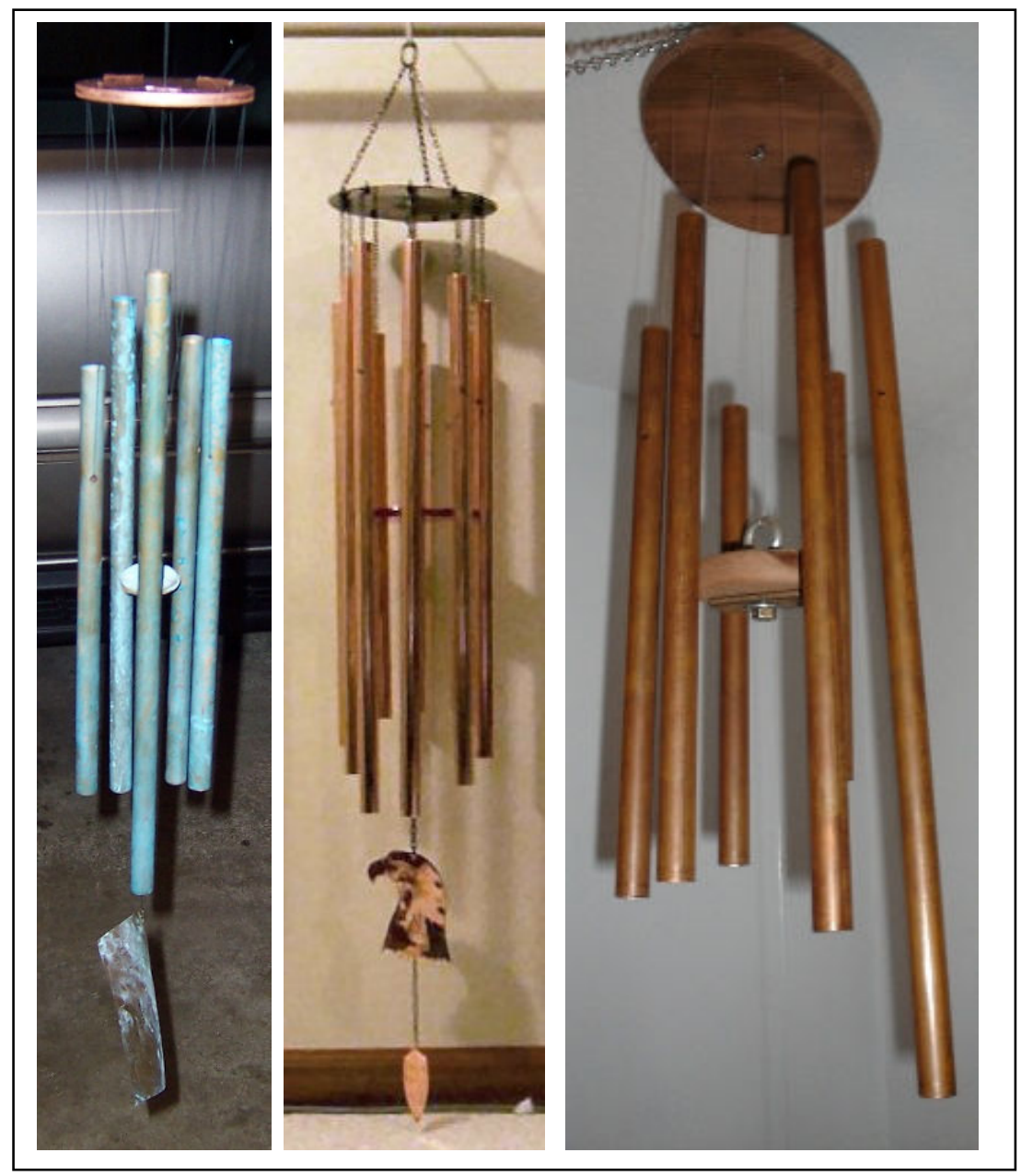

Figure 2: Three examples of student wind chimes. All three of these chimes are made using copper tubing. The picture on the right shows a typical basic set of chimes. In the middle picture there are two chimes for each note and some very detailed work on the sail. The left hand set of chimes had a chemically accelerated patina.

On the Equaled Tempered Scale shown in Table 1, for each half step up, the frequency increases by $5.95 \%$ (note: 1.0595 is the twelfth root of 2). It is desirable that the notes be tuned much more precisely than this. Most copper tubes cut based on equation 1 were within $1 \%$ of the target frequency. Steel tubes showed a slightly greater error often 3 or 4 percent. When steel 
tubes are cut based on the lumped parameter model (equation 3) and the results of initial tests, the resulting tubes were measured to be generally within $0.3 \%$ of the target frequency.

\section{Reflections}

Overall the project worked well and met my key goals of providing students with a design project that included some creative synthesis, some specific analysis, some physical/special reasoning and iteration of the design concept. The project was simple to construct and all groups were able to construct it using their own resources (with the precaution of making sure each group had a "shop" expert). In addition, these projects were completed in a short period of time allowing time for additional projects in the course. I will be using this project again in future classes.

In the future, I would include some additional structure and resources for the project management system. This would likely include some required milestones (e.g., preliminary design including note selection, tubing selection and length calculation, initial testing of a limited number of tubes for note accuracy, testing of complete wind chime with sufficient time to refine sail, hammer and support). It would also be fairly easy to change this project to one of building a musical instrument such as a xylophone.

This project was completed in five weeks to allow for multiple projects in the class. However, it is not necessary to complete it in this short a period of time. During the five-week period all assignments were directly related to the project. This project would naturally expand if assignments unrelated to the project were being completed. For a semester long project additional expectations might include more background research, detailed evaluation of alternative chime materials, a complete intermediate design for review, analysis of market acceptance issues and estimation of production costs. A particularly valuable addition could be an economic analysis of producing and selling the wind chime.

\section{Acknowledgement:}

I am indebted to Professors Jim Shaffer and Rodger Ruggles of Lafayette College for introducing me to the idea of using a wind chime as an introductory design project.

\section{Appendix:}

Survey questions asked to aid in setting up groups:

1. What branch of engineering do you expect to major in:

$$
\begin{aligned}
& \text { Computer Engineering } \\
& \text { Electrical Engineering } \\
& \text { Mechanical Engineering } \\
& \text { Other }
\end{aligned}
$$$$
\text { (please specify) }
$$

2. How much experience do you have operating simple hand tools in wood or soft metal (saws, hand drills ...)

No experience

Some experience at home with hand tools (manual and power)

School experience (shop classes)

Job experience with hand tools 
Experience with machine shop equipment

Other

3. Do you have access to a shop with hand or power tools that you are qualified and allowed to operate?

No access to shop equipment

Access to simple home hand tools

Access to portable hand power tools (drills, saw ...)

Access to a full shop

Other

4. How much musical background do you have?

Cannot carry a tune given a bucket

Three cords on a guitar

Play an instrument or have been in a vocal music group

Background in playing an instrument and in music theory

Other

\section{References}

1 Hesketh, R.P,. K. Jahan, A.J. Marchese, T. R. Chandrupatla, R. A. Dusseau, C. S. Slater, and J. L.

Schmalzel, "Multidisciplinary Experimental Experiences in the Freshman Clinic at Rowan University," Proc. Conf. Amer. Soc. Eng. Educ., Session 2326 (1997).

2. Quin, R. G., "E $\quad$ Introductory Engineering Test, Design and Simulation Laboratory," J. Eng. Ed., 82(4) 223-226, October 1993.

3 Farrell, S., R. P. Hesketh, J. A. Newell, and C. S. Slater, "Introducing Freshmen to Reverse Process Engineering and Design through Investigation of the Brewing Process," Int. J. Eng. Ed., 17(6) 588-592 (2001).

4. Johnson, R., and L. Anneberg, "Sundials Make Interesting Freshman Design Projects," Proc. Conf. Amer. Soc. Eng. Educ., Session 2793 (2002).

5 Soysal, O. A., "Project Based Learning of Energy Conversion Principles at Freshman Level," Proc. Conf. Amer. Soc. Eng. Educ., Session 2533 (2002).

6. Harvey Mud paper.

7. Baxter, G.W. and Hagenbuch, K.M., “A student project on wind chimes,” Phys. Teach. Vol. 36, pp. 204208, (April 1998).

8. Harris, R. W. "Using Wind Chimes to Introduce the Physics Course," Phys. Teach. Vol. 38, pp. 218-219, (April 2000).

9. $\quad$ Oliver, D.L.R., "Hollow-tube chimes," Phys. Teach. Vol. 36, pp. 209-210, (April 1998).

10. Suits, Brian, "Make your own wind chimes," http://www.phy.mtu.edu/ suits/windchime.html, n.d., accessed, 12/2004.

11. “Chuck's Chimes," http://www1.iwvisp.com/cllsj/windchimes/, n.d., accessed, 12/2004.

12. Kirkpatrick, Jim, "Making Wind Chimes," http://www.metalwebnews.com/howto/wchime/wchime.html, (5/5/96) accessed 12/2004.

13. Lee Hite, "An Engineering Approach to Wind Chime Design or What Makes Toast, Toast ?," http://home.fuse.net/engineering/Chimes.htm, accessed 12/2004.

14. Casey, Jay, "The wind chime project," http://www.twinlakes.k12.in.us/schools/web/jcasey/windchimes.htm $(02 / 03 / 04)$, accessed 12/2004.

15. Lowes, "Making Pipe Wind Chimes," http://www.lowes.com/lkn?action=howTo\&p=HomeDecor/WindChimes.html\&rn=RightNavFiles/rightNav HomeDecor\#chimes, (2003), accessed 12/2004.

16. Grace Note Windchimes, Inc. http://www.gracenotes.com/chimepart.html, 2/2004, accessed 12/2004. 
17. Furstner, Michael, "Jaz Class: 3. Scales \& Chords in all keys, “ http://www.jazclass.aust.com/contents.htm\#3 (2004), accessed 12/2004.

18 Voland, G., Engineering By Design, $2^{\text {nd }}$ Ed., Pearson Prentice Hall (2004).

19 Moor, S.S. and Drake, B.D., "Addressing Common Problems in Engineering Design Projects: A Project Management Approach,” Journal of Engineering Education, Volume 90, No. 3, pp. 389-395 (July 2001).

20 Moor, S.S , "Coffee on Demand: a Two Hour Design Problem," Chemical Engineering Education, Vol. 36, No. 1, (Winter 2002).

21 Callister, W. D., Materials Science and Engineering: An Introduction, $2^{\text {nd }}$ Ed., Wiley, 1991, pp 117, 738,739 .

22 Peterson, Mark, "Resources to Accompany Musical Analysis and Synthesis in Matlab,"

http://amath.colorado.edu/pub/matlab/music/, 11/2004, Accessed 12/2004. The article this website references is:

Peterson, Mark, "Musical Analysis and Synthesis in Matlab," MAA's College Mathematics Journal Vol. 35, No. 5, November 2004, p.396-401.

23 Forinash, K., Richie, J.P., and Jones, T., "Wind chime physics," Am. J. Phys. Vol. 58, No. 1, pp. 82-83 (January 1990).

24 McCreight, Tim, The Complete Metalsmith, Davis Publications (1991), pp. 35, 36.

\section{S. SCOTT MOOR}

Scott Moor is an Assistant Professor of Engineering and coordinator of First-Year Engineering at Indiana University Purdue University - Fort Wayne. He received a B.S. and M.S. in Chemical Engineering from M.I.T. After over a decade in industry he returned to academia at the University of California at Berkeley where he received a Ph.D. in Chemical Engineering and an M.A. in Statistics. He is a registered Professional Chemical Engineer in California. 